\title{
Twentieth Century Wanzams among the Asante People of Ghana: A Historical Study of the Facts on Male Circumcision
}

\author{
Samuel Adu-Gyamfi' ${ }^{1}$, Prince Osei-Wusu Adjei ${ }^{2}$ \\ ${ }^{1}$ Department of History and Political Studies, Kwame Nkrumah University of Science and Technology (KNUST), \\ Kumasi, Ghana \\ ${ }^{2}$ Department of Geography and Rural Development, Kwame Nkrumah University of Science and Technology \\ (KNUST), Kumasi, Ghana \\ Email: mcgyamfi@yahoo.com, princeosei2@hotmail.com,
}

Received 6 August 2014; revised 4 September 2014; revised 23 September 2014

Copyright (C) 2014 by authors and Scientific Research Publishing Inc.

This work is licensed under the Creative Commons Attribution International License (CC BY). http://creativecommons.org/licenses/by/4.0/

(c) (i) Open Access

\section{Abstract}

This paper studies the history of circumcision amongst religious and traditional societies and the arguments on the medical or non-medical essence of the practice. The paper further highlights amongst the Asante people of Ghana, a practice argued to have been introduced by Islamic Wanzams who are severally referred to as Muslim Circumcision Surgeons. Often circumcision amongst communities in West, Southern Africa, Asia and other Aboriginal groups has been spurred on by customs and traditions [1]. Yet the case of Asante was different. Hence attention has been paid to the history of circumcision amongst the people of Asante. More significantly, the health implications associated with circumcision surgery in Asante have been highlighted. Possible benefits from the practice of circumcision and the potential dangers associated with it, especially the operations of the Asante circumcision surgeons (Wanzams) have been amply scrutinised in the narrative. In the conclusion, attention is paid to some of the scientific arguments for male circumcision. The study is purely qualitative relying on documentary and non-documentary sources. Some of the documentary sources have been gleaned from journal articles, news papers and books etc. The non-documentary data have been sourced from interviews. Both the documentary and non-documentary sources have been thematically pieced together to form a social history of medicine narrative which has potential ramifications on the essence of male circumcision by Wanzams, as well as the need for further research, training and dialogue in the practice in Ghana and Asante in particular.

\section{Keywords}

Wanzams, Asante, Circumcision Surgeons, Circumcision, Quran 


\section{Introduction}

The practice of circumcision dates back to pre-history [2]. Dunsmur and Gordon (1999) in their writing of the The History of Circumcision associated with the position of the English Egyptologist, Sir Grafton Elliot Smith's suggestion that circumcision was one of the features of a heliolithic culture which some thousand five hundred years ago spread over much of the world. Significantly the practice of circumcision originated independently within several different cultures in Africa, the then New World as discovered by Columbus, the people of India and South East Asia as well as the Australian Aborigines among others. The procedure has been performed for religious, cultural and medical reasons. However the latter has only become fashionable since the rise of modern surgery in the Nineteenth Century [2].

Some historians claimed circumcision was a religious rite performed on royalty, while others were convinced it was used as a mark of slavery [3]. The latter view is the basis for the theory that the Jews, having undergone compulsory circumcision while they were slaves in Egypt adopted the procedure as a ritual and later incorporated its practice into the Old Testament (Genesis 17: 10 - 14) as a symbol of a covenant between God and man [4]. This argument however is not dissimilar from the traditional Asante views before the practice of circumcision was brought into Asante by Muslim Wanzams. WANZAM is a corrupted Hausa term for a traditional male circumcision specialist or traditional surgeon [5]. The view that circumcision amounted to scarification and mutilation which could be done only to those who were not freeborn was not assailed by the people of Asante by the eve of the twentieth century Ghana. Again, circumcision was also practiced by some Christians; there is a Seventeenth Century painting that shows circumcision as a religious ritual performed by a bishop [6]. What is perhaps more fascinating is that circumcision sprung up independently in so many parts of the world. In other communities, it was performed as a puberty rite and sometimes immediately before marriage. The reasons for circumcision, whether symbolic, practical or both, are as varied as the people who practice it, and include the beliefs that it is a test of a man's ability to withstand pain.

The aim of this article is to highlight the case for the positive impact of male circumcision of the Wanzams (Muslim circumcision surgeons) among the Asante people of twentieth Century Ghana. It seeks to postulate strategies for the enhancement of the practice of male circumcision amongst the Asante people of Ghana in general within the period under review and highlights its relevance in the twenty-first century. The study also aims at encouraging the training and re-training of Wanzams in Ghana. It is imperative to know that when best practices are not continuously ensured, male circumcision by Wanzams would create the space for medical complications and the spread of diseases.

\subsection{Procedure and Methods}

The study is severally qualitative, employing both primary and secondary sources. The primary data were sourced from oral interviews of Traditional Circumcision Surgeons (Wanzams) living in selected communities in Kumase including Allah Bar, Moshi Zongo, Aboabo, Sawaba in the Ashanti region of Ghana which were purposively sampled. The criterion for their selection was based on the longevity of their practice as well as their knowledge of the indigenous folklore. Secondary data were sourced from journal articles and books. These sources have either been used to corroborate or complement each other. Primary informants for instance narrated the histories of circumcision surgery within the period under review. In cases where they are practitioners, in-depth interviews were used to enable them recount the nature of their practice from past to present, emphasizing the central theme in history, continuity and change. The benefits and challenges associated with the practice of circumcision and the general histories among other things associated with it were derived from the interviewees. Journal articles, news paper articles were also important sources of data. The information gathered from the respective sources has been thematically presented.

\subsection{Research Questions}

This paper provides answers to the following research questions:

- Who are the Wanzams?

- How was circumcision practised among the Asante people in the past?

- How was circumcision practiced among the Asante within the period under review?

- What religious connotations were associated with the practice of Wanzams? 
- What health implications are associated with the practice of Wanzams?

\subsection{Origins and Practice of Circumcision}

The Arabic word used for circumcision are Khitan for males and Khafd for females. The syllables Kh-t-n belong to the primitive Semitic language, as they occur in the same or cognate forms in North-Semitic languages. This circumcision is a primitive custom and an old Arabian tradition and was not introduced initially by Islamic faithfuls. This is evident from the fact that circumcision is not mentioned in any form in the Holy Quran, and in Muslim societies the practice is attributed to the Prophet of Islam. For this reason, circumcision acquired the status of Sunnah (Prophets Tradition) although the tradition is attributed to the Prophet Abraham [7]. It is further recognized in hadith (the sayings of the Prophet Mohammed) that circumcision belongs to pre-Islamic institutions [7].

Muslims wait until the child is ten to twelve years old, a practice that may also be based on scripture even though circumcision is never mentioned in the Quran; Abraham's eldest son, Ishmael, from whom Muslims claim to be descended, was circumcised at puberty. In some African groups, circumcision is performed at birth. In Judaic societies, the ritual is performed on the eight day after birth, but for Muslims and many cultures, it is performed in early adult life as a "rite of passage", e.g. puberty or marriage. Al-Mawardi stated that the chosen time is the seventh day after birth, but it can be carried out up to the fortieth day after birth, or thereafter until the age of 7 years, depending upon the health of the child at the time [8]. The prevalent practice in Pakistan is that children born in hospitals are circumcised within few days before discharge, and the rest when aged 3 - 7 years. In rural areas most are circumcised when aged 5 - 7 years and occasionally after adolescence.

None of the ancient cultures which practiced circumcision has traditionally claimed that the ritual was introduced as a sanitary measure. African ethnic groups, Arabs, Jews, Muslims, and Australian Aboriginals explain it in different ways. However, divine command, tribal identification, social role, family obligation, respect for ancestors and promotion of self-control figure prominently. Jewish authorities make no mention of hygiene, let alone sand, but place stress on the religious significance of circumcision as an outward sign of the Covenant between God and His people [9]. The Kaguru of Central Tanzania explain circumcision (practiced at puberty on both boys and girls) in terms of enhancing gender differentiation and social control. They consider the uncircumcised penis unclean because its moistness makes men resemble women, whose wet and regularly bleeding genitals are considered polluting.

It was only in the late nineteenth century, when mass circumcision was introduced for "health" reasons, such as control of masturbation, that doctors sought legitimacy for the new procedure by attempting to explain its origin in terms of hygiene. One of the first English surgeons to make the connection was James Copeland, who introduced the idea that "the neglect of circumcision in Christian countries" was a common cause of masturbation [10]. This theme was taken up by the sanitarians in the public health movement, such as WH Cornfield, who praised circumcision as an antidote against infections. James Allen also argued that circumcision came into existence as prevention for parasitic infection s. However, (Sir) John Bland-Sutton believed that since "a long foreskin is a recognized hindrance to convenient coitus” the main purpose of circumcision was to ensure fertility [11].

Circumcisions are performed either prophylactically in the neonatal period or therapeutically at a later age. About $10 \%$ of males not circumcised at birth will eventually require circumcision. Unless there are immediate health benefits to a particular child from circumcision, it is unlikely that the procedure itself could be considered as therapeutic. The circumcision is invasive, irreversible and major. It involves the removal of an otherwise healthy organ part. It has serious attendant risks. However, it has been argued that therapeutic circumcision must be performed for the following conditions: Phimosis. Paraphimosis, recurrent balanitis, and spareunia due to a short frenulum [12]. Also when a foreskin opening is so narrow that it obstructs urination, this is very rare [13]. This function seems more likely in boys before puberty when the foreskin is usually longer and less frequently retracted-a point consistent with the fact that most circumcising ethnicities perform the operation at puberty or later [14]. In addition, the claim that circumcision protects against sand irritation appears regularly in medical journals, both as an explanation for the ancient origin of ritual circumcision in traditional societies and as a medical justification for its performance in the twentieth century [14]. What is the evidence for this?

The only point of agreement among proponents of the numerous theories is that a practical objective such as health had nothing to do with it. This is not surprising: before aseptic surgery, any cutting of flesh carried a high 
risk of bleeding, infection and death. Travelling in Iraq in the 1930's, the English doctor Wilfred Thesiger reported that Arab boys undergoing circumcision sometimes took months to recover; in the case of one who sought treatment: His entire penis, his scrotum and the inside of his thighs were a suppurating mess from which the skin was sloughing away, the pus trickling down his legs [15]. Even today, in the age of antibiotics, scores of South African teenagers die in consequence of their bush circumcision ordeal [16].

Aaron Fink (long-time crusader for universal neonatal circumcision, and originator of the idea that circumcision was a "natural condom", and thus the perfect prophylactic against HIV-AIDS) admitted that protection against desert sand was probably not the main reason for the adoption of circumcision by the Arabs and Jews. There is no evidence that traditional/ritual circumcision practices arose as a hygiene measure [1].

It is significant to point out however, that the available records concerning the practice of circumcision in Asante confirms that the practice was not indigenous. It was imported wholesale from Muslim physicians and settlers in the territories of Asante. Unlike other cultures or societies where it formed part of the rites of passage, a transition from childhood to adulthood or from boyhood to manhood, the case of Asante was different. In fact the acceptance of the practice by the young men in Asante was met with a lot of hostility by the elderly men. It is also significant to ascertain whether there were medical reasons associated with the acceptance of the practice of circumcision into Asante. This article looks at some of the historical narratives surrounding the practice in Asante, Islamic influence as well as some twentieth century and contemporary arguments medical/health arguments for the practice of circumcision. Attention has been paid to Islamic Wanzams to find out whether it is still acceptable to encourage their practice in the twenty-first century Asante and beyond.

\subsection{Historical Analyses of the Oral and Written Facts on Circumcision}

The analyses that follow are based on the emergence and practice of Circumcision in Asante within the twentieth century. Initial emphasis is based on the first fifty years and the later focuses on the last fifty years.

\section{Origin and Practice of Circumcision among the Asante in the First Half of the Twentieth Century}

In a broader context it is understood that non-herbal medicine is severally a Muslim practice that was introduced into Asante by Muslim physicians even before the first half of the twentieth century. Bonnat recorded a Muslim from Buna who stated that Kumase contained Muslims who performed the functions of physicians to the Asantehene who held them in high regard [17]. Among the class of Muslims who came to practice in Asante especially by the first half of the twentieth century were Wanzams or circumcision surgeons. It is already explained that the Asante Nkramo and Muslims generally introduced many of the non-herbal medicaments in the twentieth century including circumcision. This notwithstanding, before the twentieth century, circumcision was an unacceptable practice in Asante and Kumase specifically because it had a negative connotation. The Asante Odehyee (royal) could not subject himself to mutilation. Donkoh adequately expounds that:

Often first generation slaves were stigmatized by reference to their linguistic difference expressed in their halting or inflected Twi. Often too, they were distinguished by cicatrisation. Ordinarily, the freeborn avoided body marks and scarification including circumcision, all of which were regarded as mutilation [18].

Ordinarily, it could be inferred from Donkoh's argument that it was non-Asante residents in Asante who indulged in circumcision. Maier has also noted intermarriages between Muslims and Asante. It was this group of people who made circumcision gain deeper roots in the Asante community by the turn of the twentieth century [18].

According to Dupuis, the Asantes without knowing the content of the Koran, were equally persuaded to believe that it is a volume of a divine creation, and consequently that it contains ordinances and prohibitions that were most congenial to the happiness of mankind in general. Further enquiries have shown that circumcision is part of Muslim medicine, which is duly prescribed by the Quran [19].

By the first half of the twentieth century an Odehyee in Asante was not permitted to opt for circumcision; such an indulgence amounted to a violation of an age-old taboo of circumcision [20]. Growing up as a young Asante boy in Kumase by the first half of the twentieth century demanded that one looked upon circumcision with contempt [20]. However, within the same period, that is, the first half of the twentieth century, intermarriages, influence of Islamic culture in Asante, made several of the indigenous people to engage in circumcision. Significantly, there was a rising chorus from young girls in Adum a suburb of Kumase demanding a change in 
the status quo. Girls in Adum sang what has been described as profane songs calling for their male counterparts to be circumcised:

"An uncircumcised penis is detestable, and those who have not circumcised should come for money from us so that they can get circumcised. We shall never marry the uncircumcised.” [20].

Circumcision was invariably becoming the order of the first half of twentieth-century Asante primarily because the mass exodus of Hausa Muslims to the south in 1898 brought the practice to Asante. However, in the first half of the twentieth century Muslims became integrated into northern chiefdoms structures but maintained their distinctiveness even in the 1920s in the south keeping to the Zongos such as Asawase, Aboabo and Moshi Zongo all in Kumase. The Muslim medicine which gained prominence in the nineteenth century was still practised in these Zongo communities in the first half of the twentieth century. The influx of the indigenous communities to these settler communities as noted earlier was persistent even in the 1920s [21]. Young women were ready to foot the bill of their male counterparts to ensure that they were circumcised. An uncircumcised penis was unattractive to them. Arguably, circumcision was not demanded by the young women on medical grounds but a circumcised penis by the first half of the twentieth century looked more decent to women. Further, the people of Asante were receptive to other cultures and practices. Patronage of circumcision by Asante boys was done secretly. The clandestine nature of indigenous patronage was much to be desired. The Wanzams mostly carried out their operations between the hours of six in the morning and five and six in the evening either in the middle of farms or places outside the settlements [20]. The time for the operation was to prevent excessive pain but the location adds to the fact that it was a practice unaccustomed to the indigenous people [20].

\section{The Art of Circumcision}

Though, the expertise of the Wanzam became highly recommended in the first half of the twentieth-century Asante, the practitioners mostly dwelt on supernatural strength in the performance of their surgical operations [19]. Chants and recitations including talismans were used by practitioners to prevent hemorrhaging. The practitioners showed that, hemorrhaging during circumcision was either caused by a competitor or sometimes by evil forces resident in the person being circumcised or the family [19]. With sharp knives produced by special blacksmiths especially during the first half of the twentieth century, the circumcision surgeon pulls the foreskin a couple of times, implants the long nail of his left thumb into the point of the foreskin, and makes a mark thereon and finally uses the sharp knife to circumcise. The operation was dexterously executed in six minutes or so without anesthetics [19]. After circumcision a herbal preparation, mostly a combination of herbs and roots was spewed by the practitioner on the fresh wound to stem the flow of blood after which the wound was dressed [19]. By 1950 as a result of modernity and European influence there was recourse to the use of antibiotics.

It is not known that the British trained medical practitioners of modern medicine in Asante had no knowledge of circumcision. However, at the government hospital in Kumase where such circumcision could be done under anaesthetics, the English doctors in charge did not perform circumcision operation because it was not a medical necessity [20]. For instance, in 1949, Britain, the colonizing country withdrew free medical service cost in infant circumcision in its newly formed National Health Service and made it an out-of-pocket cost to parents and the proportion of newborns circumcised in England and Wales fell to less than one percent. Significantly, the Colonial Administration did not pay much attention to circumcision in the Gold Coast and Asante for that matter. This as it were increased indigenous interest in Wanzams. It is significant to note that Asante boys who were circumcised received approbation from their female counterparts but were scorned and felt contemptuous in the presence of the elderly, both male and female [20]. They were to lose their rights by becoming "half-alive" and "half buried" through their circumcision [20]. Appiah writing in 1996 argued, "We had eaten of the forbidden fruit and were to pay the penalty for doing so. It was the fast traditional rule that no man could occupy a stool once he was circumcised" [20].

As early as the late 1920s there was a dispute between fathers and their sons at Adeebeba, a village near Kumase, because their sons followed the new fashion of male circumcision, disrespected Asante custom and insisted on their personal autonomy [22]. With the presence of Sunni group of Muslims in Kumase, the arrival of the Ahmadiya Movement in Asante in 1921 and the establishment of the Ahlis Sunna Wal-Jama'a in the 1950s, Muslim influence gained roots in the Gold Coast. With an admixture of influence, external contacts and egoenhancement, visits from both far and near, most of which centred in Kumase, Muslims in Kumase by 1950 had a strong foundation and influence in the city [21]. Significantly, by the middle of the twentieth century, as a re- 
sult of persistent influence of Europeans, traditional usages, beliefs, customs or rules such as panyaring, human sacrifice, the rule on circumcision became relaxed and it is suspected that occupants of stools in Asante became comrades of circumcision [21]. Over the period, with the introduction of midwifery schools in Asante, midwives engaged the services of Wanzams to train students in circumcision skills [19]. However, according to Mohammed Fuseini, in Asante, it was an unequal relationship between the modern health care practitioners and the Wanzams. The relationship was one of exploitation, which left the Wanzams unappreciated [19].

Prior to the 1940s and 1950s circumcision surgeons received gifts which included fowl, clothes and other merchandise but from the 1940s and 1950s, emphasis was shifted from the offer of gifts to payments in cash. However, the reward that came to Wazams was based on the request the practitioners made and how much their clients could offer [19]. In spite of the income circumcision surgery provided for practitioners in Asante, efforts to come together to form an association proved futile. The reason for this failure was largely personal interest on the part of individual potential members as well as lack of interest of stakeholders and the medical authorities at the time [19]. Forson has reported of the carry-over of such disregard on the twenty-first century by observing that.

The work of Wanzams has not been appreciated through any means of certification... But as the fact remains that more village folks cannot have easy access to doctors to perform "A-Septic Technique" (i.e. The free bacteria or germs) surgery on circumcision, the services of these traditional men would be needed by the village folks. This calls for the need to train and equip wanzams with modern hygienic ways and methods of circumcision [23].

Further enquiries revealed that by 1950, in Asante, Wanzams still carried out their operations without administering local or general anaesthetics and that they used homemade and unsterilized surgical instruments and bandages that were literally pieces of old rags [19] [20]. This situation indicates that in Asante and specifically Kumase, diseases and infections became transferable through circumcision.

Comparatively, in rural Turkey, mass circumcision is performed in $85 \%$ of cases by unqualified circumcisers and traditional drummers, with only $10 \%$ by health technicians and $5 \%$ by trained doctors [24]. In the Gulf States, because they are affluent, 85\% of circumcision in Saudi Arabia, the United Arab Emirates and Iran, are performed by doctors or health technicians, and only $15 \%$ by traditional circumcisers [24]. Same cannot be said for Ghana and Asante for that matter. Since the rural population are largely not surveyed and still a sizeable number of the population still rely on the activities of itinerant Muslim Wanzams.

One notable Colonial influence is that Wanzams shifted attention from the use of knives to blade. This, in essence, prevented the spread of communicable diseases. The study has found out that circumcision was not a direct medical interest of Britain hence, the British trained medical doctors in Asante and the Gold Coast in general did not provide circumcision service. This gave room for the activities of Wanzams to thrive in Asante and Kumase in particular from the 1920s to 1957. However, in the Nineteenth Century circumcision was advanced in Britain and other English-speaking countries, as a prevention for masturbation and ills believed to be caused by masturbation, and was labeled as "hygienic", a misdescription which persists [25]. "Male circumcision is lawful under English common law. It is generally accepted that, the removal of the foreskin of the penis has little, if any, effect on a man's ability to enjoy sexual intercourse, and this act is not, therefore, regarded as mutilation" [25].

It is also observed that effort by practitioners to come together in Asante to form an association proved futile. Nepotism on the part of practitioners on one hand and apathy on the part of the Colonial Administration has been found to be the cause. Generally, from the 1920s to the 1950s practitioners did not employ the Anti-Septic technique hence, transfer of infection from one person to the other was possible and the unreported cases in Asante could have been alarming [26].

Again, in Asante, there was no direct Colonial measure to retrain or train indigenous healers in modern scientific therapeutics except for rules set to prevent quackery in the indigenous healing environment. This notwithstanding, the rules set by the Colonial Administration lessened the complications the sick in Asante especially Kumase suffered from the hands of some quack indigenous medical practitioners. Colonial reform policies instigated the formation of indigenous herbal associations in Asante and elsewhere in the Gold Coast that sought free and unhindered practice by its members especially from the Colonial Administration [26]. Future indigenous medical associations in Asante were faced with the issues pertaining to nepotism on the part of literate members who were not practitioners themselves and did not have appreciation of the nuances of the indigenous medical field. Again, there were several internal unrests among association members in Kumase as a result of 
disrespect and disregard shown to chiefs or District Commissioners by association members. There was also the so-called interference of modern medical authorities, which further disrupted the indigenous medical drive during the first half of the twentieth century Asante [26]. This notwithstanding, the archival records do not point towards any Wanzam or an Association for Indigenous Circumcision Surgeons.

From the 1950s onwards some of the emerging indigenous medical fraternities in Asante aimed at fostering cooperation with modern medical bodies like the Ghana Medical Association and the Ghana Academy of Sciences in the promotion of the science of herbalism as well as psychiatric and psychosomatic treatment. Significantly, what underscores the formation of such indigenous medical fraternities in the Gold Coast and Asante specifically was that during the 1950s in Kumase the indigenous medical profession was well organized. Members were bonded with a code of conduct to ensure that they did not engage in practices that put the names of the associations in disrepute and further to practice in any medicine that endangered human life [26].

In the 1930s, as part of the efforts by the Colonial Administration to streamline the activities of indigenous medical practitioners in Asante and Kumase specifically, registration licences were issued to practitioners who were found to be genuine by references the Nsumankwaahene received from chiefs in Asante whose jurisdictions the said practitioners wanted to practice their medicine [27]. Indigenous practitioners were barred by regulation to charge beyond thirteen shillings. This provision was to check profiteering. Licensees were charged by the Native Authority not to defraud, extort or charge unreasonable fee. Those who were found charging unreasonable fee or defrauding people were summarily convicted with a fine not exceeding twenty-five pounds or with an imprisonment with or without hard labour not exceeding three months or both. By the 1940s, the Colonial Administration got the Colonial Police involved to ascertain through police investigations whether indigenous healers who applied for licenses to commence operation had no dangerous practices in their medicines. Such police investigation reports produced a class of indigenous practitioners who became vigilant and made efforts to live up to the expectations of the Colonial Administration [27]. The above notwithstanding the Colonial records in Ghana and Asante for that matter also do not point us towards the fact that there was any Association for Wanzams since it was already known that the Colonial Country, Britain, did not have much interest in circumcision and therefore did not pay particular attention to its local or indigenous practitioners.

One of the noticeable influences of the Colonial Administration on indigenous medical practices especially with maternal and infant health care was the setting up of midwifery schools and scholarships for pupils as well as the building of the Child Welfare Clinic in Kumase that met the needs of pregnant women and children. The establishment of such training schools produced modern health care professionals who lessened the burden on the TBAs who were not endowed with modern techniques of child delivery and health care [27]. Efforts by the Colonial Administration also had the propensity to lessen the number of deaths of mothers during delivery. Yet, the study has found that apart from Kumase there were several unreached territories so far as modern maternal health care delivery was concerned. Hence, one of the innovative ideas was when the Colonial Administration legislated that unqualified midwives, here referring to TBAs in Kumase, be registered by Dr. Chappell, the Director of Medical Service. Firstly, the intent was to prevent quackery, and secondly, to find out the number of efficient TBAs and also modern health professionals who were meeting the dire health needs of pregnant women and their children [27]. Even though the legislation was ideal, it did not pass beyond Kumase, suggesting that the rest of the Asante population were still left in the hands of TBAs whose genuineness or quackery could not be easily ascertained. Again, the Colonial records do not show that there was any training in circumcision surgery or re-training and tooling of traditional circumcision surgeons (wanzams) to support or provide circumcision services in the colonial medical establishments. These wanzams mostly moved door to door in the rural communities as itinerant wanzams to support the TBAs by circumcising babies in their homes. Some of the TBAs over the period have learnt the art of circumcision and therefore combines their services as traditional pediatricians with traditional circumcision surgery.

\section{Conclusions}

Although there are several arguments which have been raised against the practice of male circumcision, especially those practiced by traditional or religious circumcision surgeons like the Wanzams, modern scientific arguments have generally supported the practice of male circumcision and the benefits associated with it have been highlighted by several scholars in Europe, America and Africa for that matter. For instance it has been argued that cancer of the penis may be prevented by circumcision [28]. Dodge and associates found a decreased 
incidence of cancer of the penis among circumcised African men [29]. Though the mortality of this disease is low, the risk of death from circumcision is probably lower. It has been buttressed that circumcising the newborn facilitates penile hygiene, prevents cancer of the penis and decreases the incidence of genital herpes in later life. More importantly, neonatal circumcision is associated with much lower morbidity and mortality and with lower costs than therapeutic circumcision. Thus, it has been invariably suggested by Burger that prophylactic circumcision is recommended for the male population as a whole [4].

Most circumcisions done in Ghana amongst the Asante people after the 1940s were mostly and severally performed on children during the eight day and this might account for the possible little cases or no mortality cases in circumcision. For the male population as a whole, we recommend circumcision because of its medical and economic advantages. For the individual, the known benefits usually outweigh the risks. Hemorrhage, infection and other immediate complications of circumcision have been reported. Most are easily treated; those that are not are very rare. For example, Meatitis is more common in circumcised infants but it is also easily treated. Significantly, it has been emphasized that circumcision facilitates penile hygiene, an argument which has since not been totally discarded even by those who do not attribute any medical or health essence to circumcision. Circumcision has the proclivity to ensure a lower prevalence of herpes genitalis. Again it is more common for the uncircumcised to be suffering from balanoposthitis [30]. The high incidence of balanoposthitis in males with diabetes makes prophylactic circumcision particularly advantageous for individuals at high risk of diabetes [31]. Recurrent balanitis, phimosis, a short frenulum and paraphimosis are indications for circumcision. Though these conditions are not completely prevented by circumcision, their incidence would be reduced by neonatal circumcision [30].

In Ghana and Asante in particular, the Wanzam with the use of no statures and with unsterilized instruments but with ashes of burnt wood was able to establish hemostasis. To alleviate the trauma of pain, the occasion is converted into a celebration where relatives and guests are invited. A medical necessity is not established but a traditional naming ceremony is done. In different countries, circumcisions are performed by local traditional barbers, drummers and health technicians, and consequently complications often go unreported. It is however difficult to quantify the impact these have on the male children or adults who undergo circumcision surgery. It is important to point out that these complications go unreported because for instance in the case of Ghana, several of the practitioners are not found in the regular health service.

Primary infection and hemorrhage are encountered during and after circumcision. Circumcision is a widespread practice which is greatly influenced by cultural and religious traditions. It is decided by the parents based on the existing cultural and religious aspects. Ideally it has been argued that the operation should be performed by qualified surgeons in hospitals. But in developing countries like Ghana, the proper training of health technicians would help to reduce the preventable complications of circumcision. Significantly, it is suggested that venereal diseases are more prevalent amongst uncircumcised males [32].

\section{Recommendations}

To make the benefits of male circumcision count in traditional communities like Asante especially those practiced by itinerant Wanzams, there is the need for the Wanzams to undergo refresher courses to learn modern ways or techniques of circumsion. Significantly, even in the twentieth and the beginning s of the twenty-first century Ghana, there has been increasing reports of the use of unhygienic and unsterilized instruments by some practitioners resulting in serious health consequences [5].

There is also the need to have an enforceable law that ensures that all Wanzams are enjoined by law to go for refresher courses from time to time most especially those in Asante and the hinterlands. Reports in the year 2006 confirm the need to do so. For example, speaking to the Times, the Director of the Muslim Family Counselling Services, Alhaji Baba Issa, argued among other things that refresher courses or programmes aimed to address growing public concerns about safe and hygienic circumcision techniques has not been patronised. A noticeable example was the poor attendance of the special training programmes organized by the Ussher Polyclinic in Accra [5].

It is significant to stress that the Ussher Polyclinic in Accra, Ghana, has since 1994 trained more than 200 Wanzams from Maamobi, Nima, Sukura, Madina, Sabon Zongo and other Muslim dominated communities where the services of Wanzams are most patronized.

According to Alhaji Baba Issa, an opinion leader who has shown keen interest in the operations of Wanzams, 
his organization had since 1992 collaborated with the Ussher Polyclinic in Accra to mobilize the Wanzams for training but the initial interest had abated with the failure of the new crop who took over from either fathers or masters to attend the training sessions [5]. It is important to stress that similar initiatives should be put in place in Asante and other hinterlands to ensure that the benefits of male circumcision is fully derived and the potential risk associated thereof minimised.

It has been hinted that there is an Association of trained Wanzams in the Greater Accra region of Ghana [5]. This was not so especially within the twentieth century in the Asante region of Ghana. It should be helpful if such associations are formed to foster cooperation in the area and to enhance their practice, especially when they are able to subject themselves to peer review and enjoin themselves to resort to modern hygienic practices. With the spate of increasing concerns for HIV/AIDS, the need for such associations cannot be underestimated. In fact meetings could be held by these associations once they are formed and start work, to discuss issues pertaining to transferable diseases through circumcision and potential occupational hazards.

It can be surmised however that, based on religious reasons (Islam and Christianity) and customary reasons most Ghanaians and Asante for that matter will continue to tread in the domain of circumcision. Yet for the role of the Wanzams to continue to thrive they will have to be absorbed into the modern health services, to ensure proper regulation and training that will make their practices more hygienic, enhance their modern knowledge in the field and to also make it possible for non-religious educated middle and upper-class members of the Ghanaian society in twenty-first century to embrace them. However, it is important to stress that their roles will still remain relevant in Islamic communities in Ghana and several hinterlands in Ghana where, midwifery and public health units and compounds are not readily available or accessible.

\section{References}

[1] Dunsmuir, W.D. and Gordon, E.M. (1999) The History of Circumcision. BJU International, 83, 1-12.

[2] Doyl, D. (2005) Ritual Male Circumcision: A Brief History. Journal of Royal College of Physicians, 35, 275.

[3] Kaplan, G.W. (1977) Circumcision: An Overview. Current Problems in Pediatrics, 7, 1-33.

[4] Guthrie, R.B. (1974) Why Circumcision? Pediatrics, 54, 362-364.

[5] Appiah, V. (2006) "Wanzams” for Refresher Course. 11 February 2006.

[6] Waszak, S.J. (1974) The Historic Significance of Circumcision. Obstertics and Gynecology, 7.

[7] Rizvi, S.A.H., Naqvi, S.A.A., Hussain, M. and Hasan, A.S. (1999) Circumcision: A Muslim View. BJU International, 83, 13-16.

[8] Mustafa, A., Ahmed, T.V.N. and Persuad, S.F. (1987) Rules for Cleanliness in Islam. Presented at The 1st International Conference for the Scientific Aspects of the Quran and Sunnah in Islamabad, Pakistan.

[9] Weiss, C.A. (1962) Worldwide Survey of the Current Practice of Millah (Ritual Circumcision). Jewish Social Studies, 24, 30-48.

[10] Copland, J. (1997) Pollution. Dictionary of Practical Medicine. 4 vols, Longmans, London, 1844-1858.

[11] Bland-Sutton, J. (1870) Circumcision as a Rite and as a Surgical Operation. BMJ.

[12] Whelan, P. (1977) Male Dyspareunia Due to Short Frenulum: An Indication for Adult Circumcision. British Medical Journal, 2, 1633-1634.

[13] Herrera, A.J. and Trouerntrend, J.B.G. (1979) Routine Neonatal Circumcisions. American Journal of Diseases of Children, 133, 1069-1070.

[14] Paige, K.E. and Paige, J.M. (1981) The Politics of Reproductive Ritual. University of California Press, Berkeley.

[15] Thesiger, W. (1964) The Marsh Arabs. Longman, London.

[16] (2003) Astonishing Indifference to Deaths Due to Botched Ritual Circumcision. SAMJ.

[17] Maier, D. (1979) Nineteenth-Century Asante Medical Practices. Comparative Studies in Society and History, 21, 63-81. http://dx.doi.org/10.1017/S0010417500012652

[18] Donkoh, W.J. (2007) Legacies of the Transatlantic Slave Trade in Ghana: Definitions, Understanding and Perceptions. In: Anquandah, J.K., Ed., The Trans Atlantic Slave Trade: Landmarks, Legacies, Expectations, Sub-Saharan Publishers, Accra, 308-309.

[19] (2008) Interview with Mohammed Fuseini and Mustapha Fuseini. Aboabo, Kumase, 19 February 2008.

[20] Appiah, J. (1996) The Autobiography of an African Patriot. Asempa Publishers, Accra. 
[21] Samwini, N. (2006) The Muslim Resurgence in Ghana Since 1950: Its Effects upon Muslims and Muslim-Christian Relations. 38-39.

[22] McCaskey, T.C. (2000) Asante Identities, History of Modernity in an African Village, 1850-1950. Edinburgh University Press, Edinburgh, the International African Institute, London, Indianapolis University Press/International African Library, Bloomington and Indianapolis.

[23] Forson, P. (2006) Circumcision and HIV/AIDS. The Ghanaian Times, 13 October 2006.

[24] Özdemir, E. (1997) Significantly Increased Complication Risk with Mass Circumcisions. British Journal of Urology, 80, 136-139.

[25] Price, C. (1997) Male Circumcision: An Ethical and Legal Affront. Bulletin of Medical Ethics, 128, 13-19.

[26] Constitution of the Ghana Psychic and Traditional Healing Association (1963) Correspondence between the Ghana Psychic and Healing Association and the Asantehene. 3 August 1963.

[27] (1928-1947) Manhyia Archives of Ghana, Kumase, MAG 1/17/6, Medical Hospital File.

[28] Dagher, R., Selzer, M.L. and Lapides, J. (1973) Carcinoma of the Penis and the Anti-Circumcision Crusade. Journal of Urology, 110, 79-80.

[29] Dodge, O.G., Linsell, C.A. and Davies, J.N. (1963) Circumcision and the Incidence of the Carcinoma of the Cervix: A Study in Kenya and Uganda Africans. East Africa Medical Journal, 40, 440-444.

[30] Osipov, V.O. Balanoposthitis. http://emedicine.medscape.com/article/1124734-overview

[31] Callender, G.W. and Willet, A. (1965) Brief Notes of the Surgical Practice of the Hospital. St. Barts Hosp Rep. 1, 3562.

[32] Green, E.C. and Dupree, J.D. (1993) Indigenous African Healers Promote Male Circumcision for Prevention of Sexually Transmitted Diseases. Tropical Doctor, 23, 182-183. 
Scientific Research Publishing (SCIRP) is one of the largest Open Access journal publishers. It is currently publishing more than 200 open access, online, peer-reviewed journals covering a wide range of academic disciplines. SCIRP serves the worldwide academic communities and contributes to the progress and application of science with its publication.

Other selected journals from SCIRP are listed as below. Submit your manuscript to us via either submit@scirp.org or Online Submission Portal.
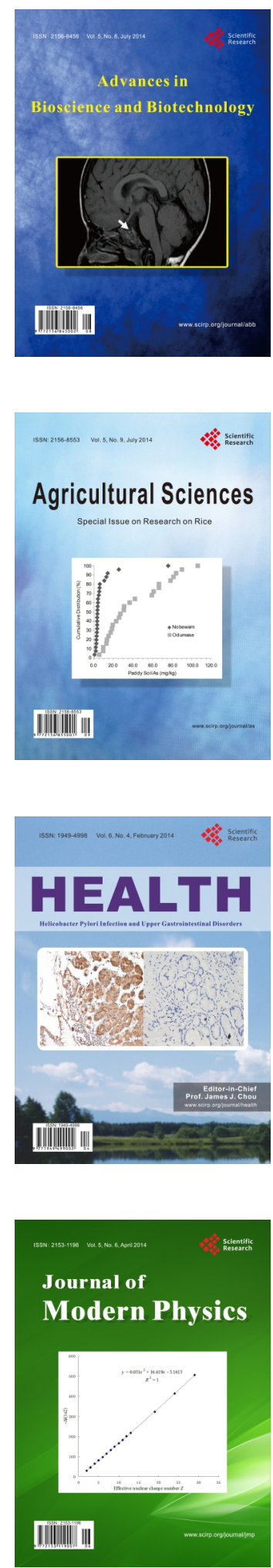
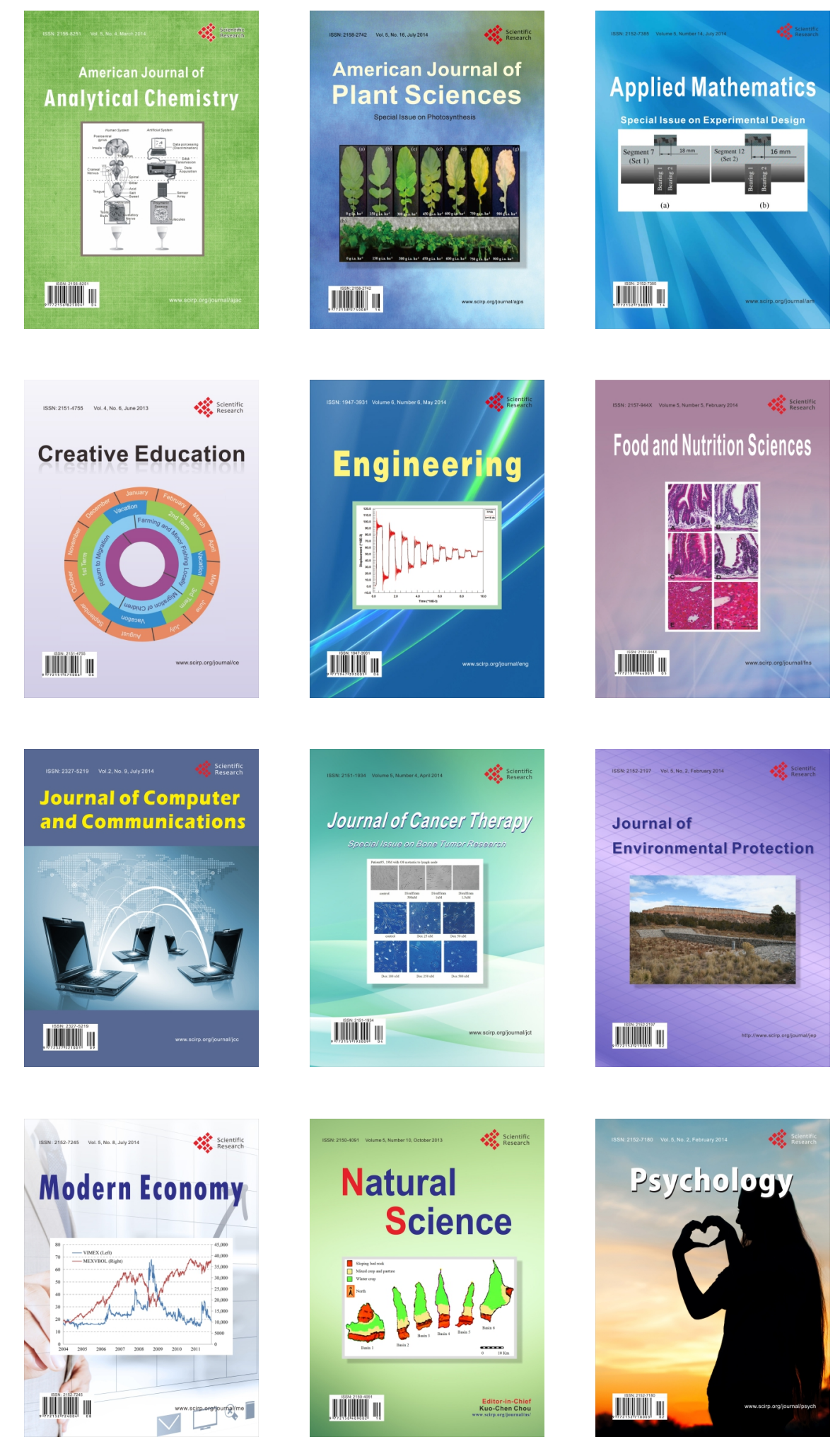